\title{
Sosialisasi Deteksi Dini Hama Wereng Menggunakan Teknologi Informasi di Desa Cabean, Kecamatan Sawahan, Kabupaten Madiun
}

\author{
Pradityo Utomo ${ }^{1}$, Arief Budiman ${ }^{2}$

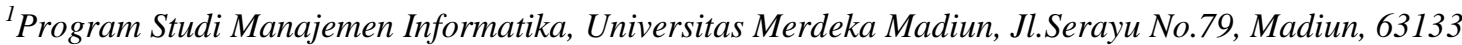 \\ E-mail:pradityo@unmer-madiun.ac.id \\ ${ }^{2}$ Program Studi Manajemen Informatika, Universitas Merdeka Madiun, Jl.Serayu No.79, Madiun, 63133 \\ E-mail: arief@unmer-madiun.ac.id
}

\begin{abstract}
Indonesia is one of the largest rice producing countries in the world. In rural areas, the majority of the population has a livelihood as rice farmers. Being a farmer also has several obstacles, one of which is the attack of planthopper on rice plants. This makes the yield less optimal. Farmers must be vigilant from the outset against planthopper pests. Onward with the development of technology, farmers can use information technology as a learning tool to detect planthopper pests early and control them. The result of the development of information technology that every community uses and owns is an Android-based smartphone. For this reason, with the socialization of the application of early detection of planthopper pests and their control using biological agents can help farmers in managing rice plants. The app is made based on Android, so farmers can install the application into a smartphone to detect planthopper pests. Whereas for the control of planthopper pests selected using Biological Agent, because Biological Agents are a safer way to control planthopper pests than using pesticides. By utilizing Android applications and biological agents, farmers are expected to get maximum yields.
\end{abstract}

Keywords—: Rice; Wereng Pest; Socialization; Biological Agents.

\section{PENDAHULUAN}

\section{A. Latar Belakang}

Salah satu mata pencaharian utama warga Kabupaten Madiun adalah sebagai petani padi. Beberapa permasalahn yang sering dialami petani padi adalah kendala kurangnya pemenuhan kebutuhan air dan serangan hama. Menurut data dari Stevani (2017) pada tahun 2017 wilayah seluas 223 hektar di wilayah kabupaten Madiun terserang Hama Wereng, daerah yang terkena dampak serangan Hama Wereng adalah Desa Wonoasri, Desa Pilangkenceng, Desa Sawahan, Desa Balerejo, Desa Saradan, Desa Wungu, dan Desa Mejayan. Salah satu dampak dari serangan Hama tersebut adalah berkurangnya hasil panen sehingga pendapatan petani dari hasil panen menurun drastis, sehingga pada akhirnya banyak warga yang beralih ke mata pencaharian lain. Jika hal tersebut dibiarkan maka akan mengakibatkan harga bahan makanan pokok khususnya beras semakin tinggi. Sehingga harga jual beras semakin tinggi yang kemudian mengakibatkan daya beli masyarakat semakin menurun.

Wilayah desa yang terkena dampak serangan Hama Wereng di wilayah Kecamatan Sawahan adalah Desa Cabean. Akibat dari serangan Hama Wereng maka hasil panen padi di Desa tersebut menjadi kurang maksimal sehingga membuat subsidi beras ke wilayah lain menjadi menjadi berkurang. Jika pasokan beras berkurang, maka akan member peluang bagi beras impor untuk merebut pasar di Indonesia.

Semakin berkembangnya teknologi informasi, maka penyampaian informasi dapat dilkukan melalui teknologi informasi. Seperti yang dilakukan oleh Budiman dan Amadi (2016), pada penelitian tersebut dikembangkan sebuah website yang dapat memberikan informasi dan pembelajaran tentang kesenian tari Dhungkrek. Selain itu pada penelitian Mulyawan dan Budiman (2013) juga diperkenalkan sebuah aplikasi pembelajaran tentang tindak pidana korupsi sehingga masyarakat dapat dengan lebih mudah dalam mengidentifikasi tindak pidana korupsi. Sedangkan penelitian dalam bidang teknologi informasi yang terkait dalam bidang pertanian adalah pengembangan aplikasi Sistem Pakar Deteksi Hama Tanaman Padi yang dilakukan oleh Triono dan Tristono (2016), pada penelitian tersebut dikembangkan sebuah aplikasi yang dapat melakukan identifikasi serangan hama tanaman padi dengan melakukan input pada sebuah aplikasi berbasis website.

Oleh karena itu pada pengabdian ini akan dikenalkan sebuah situs website yang memberikan informasi terkait hama wereng dan pengendaliannya. Pada umumnya warga dalam mengendalikan hama menggunakan pestisida, tetapi di dalam situs tersebut akan diberikan informasi cara yang aman dalam mengendalikan hama wereng. Warga juga akan dikenalkan dengan sebuah aplikasi android yang dapat mendeteksi serangan wereng secara dini.

\section{B. Identifikasi dan Perumusan Masalah}

Identifikasi dan perumusan masalah dari kegiatan Pengabdian ini adalah bagaimana menjelaskan cara untuk melakukan deteksi dini hama wereng menggunakan teknologi informasi kepada masyarakat Kelompok Tani Desa Sawahan dan bagaimana menjelaskan cara aman dalam mengendalikan serangan hama wereng dengan menggunakan Agen Hayati. 
Website : http://dayamas.unmermadiun.ac.id/index.php/dayamas

\section{Tujuan Pengabdian Kepada Masyarakat}

Tujuan kegiatan ini adalah sebagai berikut:

- Untuk memberikan penjelasan tentang cara mendeteksi dini hama wereng menggunakan teknologi informasi.

- Untuk memberikan penjelasan tentang cara aman dalam mengendalikan serangan hama wereng.

\section{Manfaat Kegiatan}

Manfaat Kegiatan Bagi Warga Desa Sawahan dengan adanya kegiatan sosialisasi ini adalah, masyarakat memiliki pengetahuan cara mendeteksi dini serangan hama wereng menggunakan teknologi informasi. Selain itu masyarakat juga memiliki pengetahuan cara aman mengendalikan serangan hama wereng.

\section{METODE PELAKSANAAN}

Metode pelaksanaan sosialisasi deteksi dini hama wereng menggunakan teknologi informasi di desa Cabean, Kecamatan Sawahan, Kabupaten Madiun adalah berupa ceramah menggunakan LCD proyektor dan Laptop.

Mitra yang dipilih dalam kegiatan ini adalah kelompok tani, dalam hal ini adalah kelompok tani padi. Selain sosialisasi, juga dilakukan pendampingan. Selama pendampingan, akan dilakukan evaluasi pemahaman dari hasil sosialisasi. Hal yang dilakukan dalam evaluasi adalah mengukur kepahaman masyarakat khususnya kelompok tani dalam menggunakan teknologi informasi untuk mendeteksi serangan hama dan pengendaliannya.

\section{III.HASIL DAN PEMBAHASAN}

\section{MATERI PENGABDIAN}

\section{A. Sosialisasi Serangan Hama Wereng}

Masyarkat kelompok Tani diberikan edukasi mengenai apa itu Serangan Hama Wereng. Mulai dari macam-macam serangan Hama Wereng, siklus hidup Hama Wereng, ciri-ciri awal tanaman padi akan terserang Hama Wereng, dan bagaimana cara membangun sebuah ekosistem yang baik agar tanaman padi tahan terhadap serangan Hama Wereng.

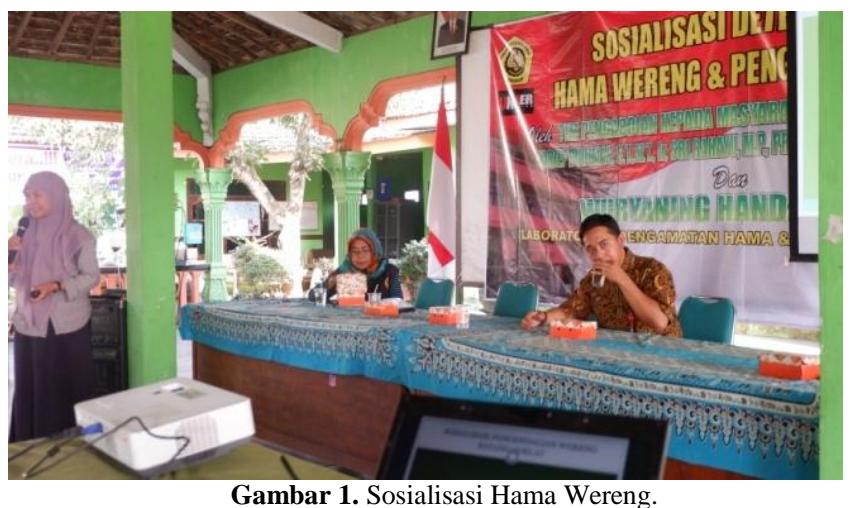

\section{B. Sosialisasi Website werengmania dan Aplikasi Deteksi Dini Hama Wereng Berbasis Android}

Masyarakat Kelompok Tani diberikan informasi mengenai pemanfaatan website www.werengmania.com untuk mempelajari tentang serangan Hama Wereng dan bagaimana cara mengendalikan serangan Hama Wereng. Selain Informasi Hama Wereng dan Pengendaliannya, pada website tersebut juga diberikan penjelasan tentang bagaimana cara pencegahan agar tidak terkena serangan Hama Wereng. Pada Gambar 2 dan Gambar 3 ditunjukkan tampilan dari halaman website informasi hama wereng.
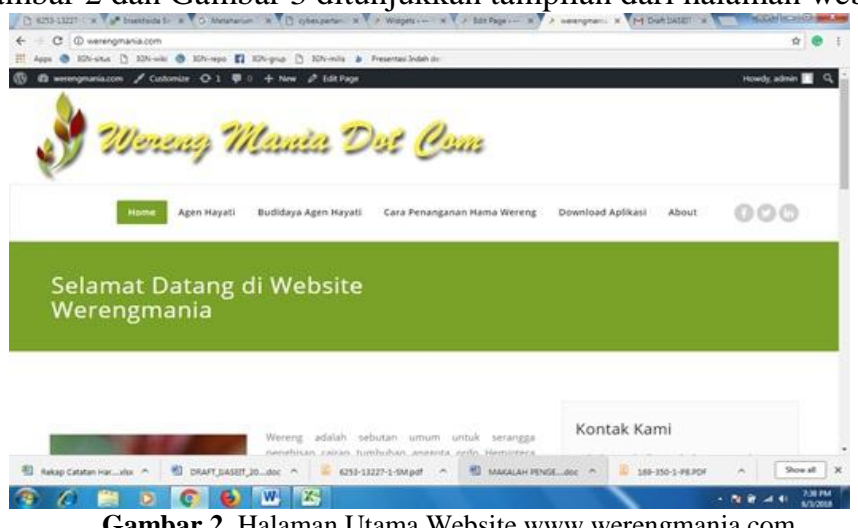

Gambar 2. Halaman Utama Website www.werengmania.com 
Website : http://dayamas.unmermadiun.ac.id/index.php/dayamas

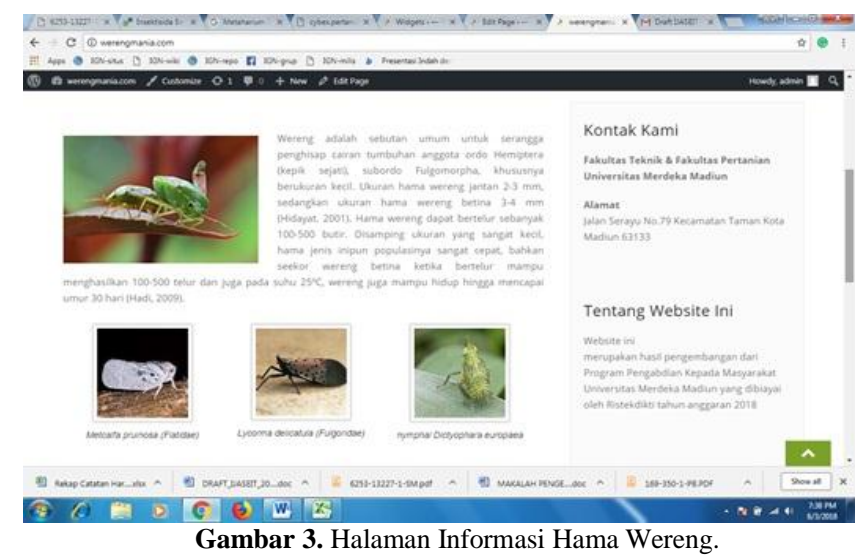

Aplikasi berbasis android dapat dipasang pada beberapa jenis ponsel dengan system operasi Android, pada PKM ini aplikasi diaplikasikan pada perangkat Smartphone Huawei Y3 2017. Aplikasi digunakan dengan cara mengambil foto batang tanaman padi yang ingin di deteksi, kemudian dari foto tersebut aplikasi akan mengirimkan data ke server dan kemudian server melakukan pengolahan data. Setelah data selesai diolah server kemudian mengirimkan jawaban ke aplikasi, tampilan penggunaan aplikasi dapat dilihat seperti pada Gambar 4 dan Gambar 5 berikut :

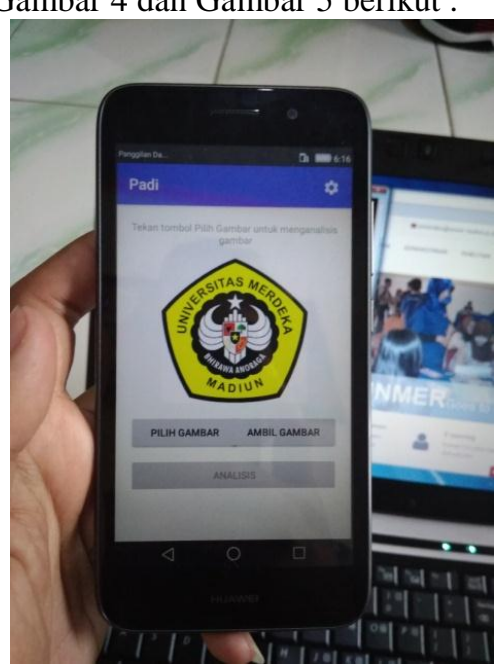

Gambar 4. Tampilan Utama Aplikasi Deteksi Dini Hama Wereng

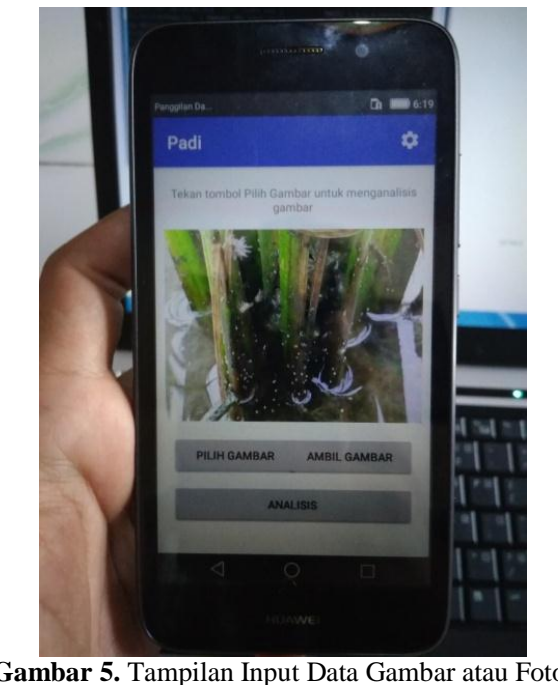

Tampilan hasil analisi dari input data foto yang dimasukkan kedalam aplikasi Deteksi Dini Hama Wereng berbasis Android dapat dilihat pada Gambar 5 berikut. 
Website : http://dayamas.unmermadiun.ac.id/index.php/dayamas

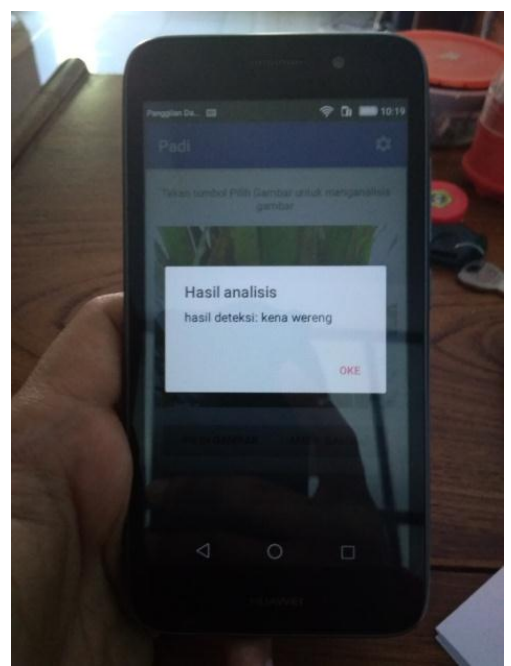

Gambar 6. Tampilan Hasil Analisis Aplikasi Deteksi Dini Hama Wereng.

\section{Sosialisasi dan Pelatihan Budidaya Agen Hayati}

Materi terakhir dari kegiatan pengabdian ini adalah sosialisasi tentang penggunaan Agne Hayati sebagai pengendali Hama Wereng, setelah sosialisasi kemudian kelompok tani diberikan pelatihan tentang pembuatan Alat Budidaya Agen Hayati, dimana tujuan dari pembuatan alat Budidaya Agen Hayati ini agar Mitra dapat mencegah serangan Hama Wereng dengan memanfaatkan Agen Hayati dan meminimalisir penggunaan Pestisida.

Untuk penggunaan Agen Hayati adalah $200 \mathrm{ml}$ untuk dicampurkan dalam satu tangki semprot berukuran 15 liter, Agen Hayati disemprotkan pada batang padi baik sebagai pencegahan maupun penanganan. Akan tetapi pada pelaksanaan PKM kali ini tepat pada musim kemarau, sehingga serangan Hama Wereng cukup minimal. Oleh karena itu penggunaan Agen Hayati saat ini lebih kepada untuk pencegahan Hama Wereng.

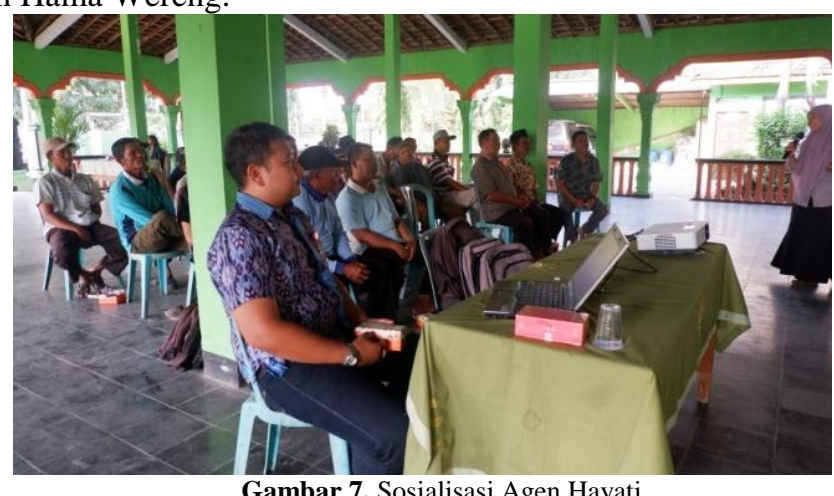

Gambar 7. Sosialisasi Agen Hayati

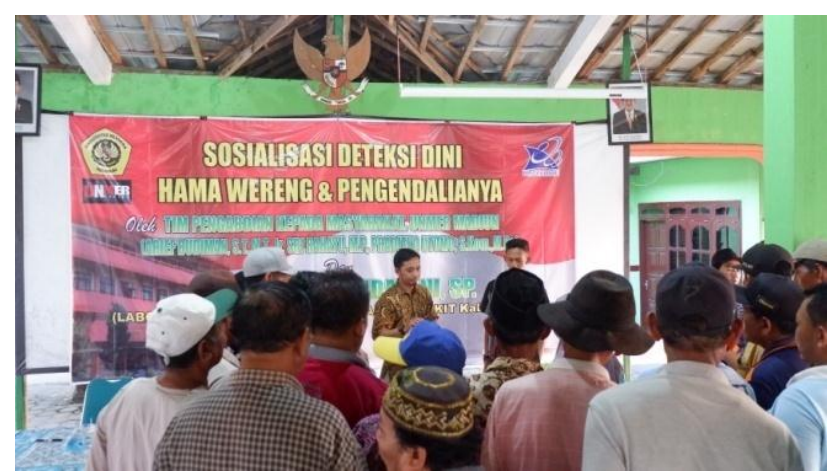

Gambar 8. Pelatihan Pembuatan Alat Budidaya Agen Hayati. 
Website : http://dayamas.unmermadiun.ac.id/index.php/dayamas

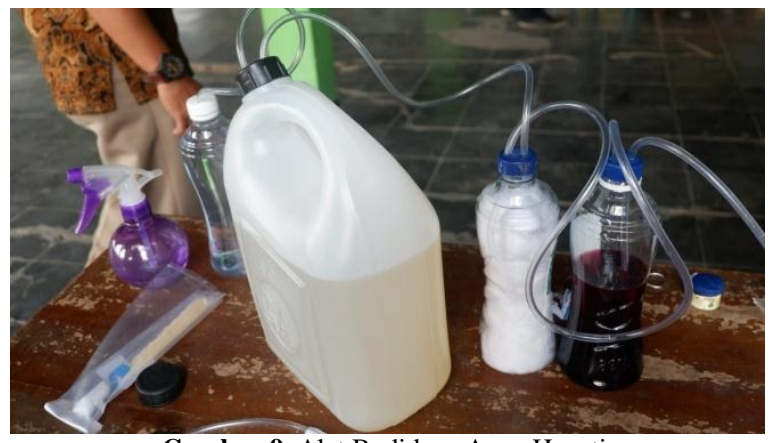

Gambar 9. Alat Budidaya Agen Hayati.

\section{Pelaksanaan Kegiatan}

Kegiatan pengabdian ini dilaksanakan pada:

Tanggal : 1 Oktober -1 Nopember 2018

Waktu : jam $15.00 \mathrm{~s} / \mathrm{d} 17.00 \mathrm{WIB}$

Kegiatan :

1. Sosialisasi tentang serangan Hama Wereng dan Identifkasi awal serangan Hama Wereng.

2. Sosialisasi aplikasi website www.werengmania.com

3. Sosialisasi penggunaan aplikasi Deteksi Dini Hama Wereng berbasis Android.

4. Sosialisasi Agen Hayati dan Pelatihan pembuatan alat budidaya Agen Hayati.

5. Setelah kegiatan sosialisasi dan pelatihan kemudian dilanjutkan dengan kegiatan pendampingan Kelompok Tani dalam melakukan budidaya Agen Hayati.

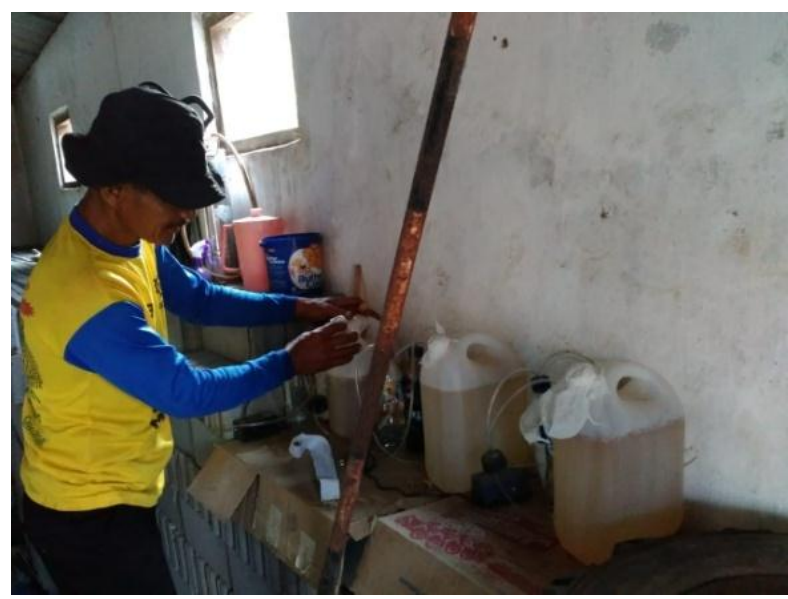

Gambar 10. Agen Hayati Kelompok Tani Dukuh Benguk.

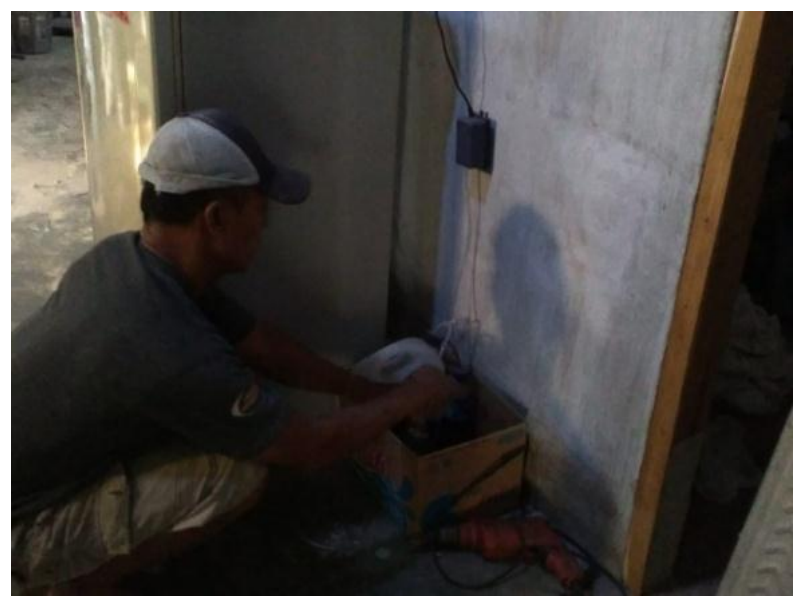

Gambar 11. Agen Hayati Kelompok Tani Dukuh Banyak. 
Website : http://dayamas.unmermadiun.ac.id/index.php/dayamas

\section{E. Hasil Kegiatan}

Hasil yang diperoleh dari kegiatan sosialisasi di Desa Cabean, Kecamatan Sawahan, Kabupaten Madiun adalah :

1. Masyarakat khususnya kelompok tani dapat mendapat informasi tentang hama wereng, mendeteksinya, dan cara pengendaliannya dari situs website werengmania.com

2. Masyarakat khususnya kelompok tani dapat menggunakan aplikasi android untuk mendeteksi hama wereng

3. Masyarakat khususnya kelompok tani dapat membuat agen hayati untuk mengendalikan hama wereng.

Untuk prosentase keberhasilan dari sosialisasi dan pendampingan dapat dilihat pada Gambar 1.

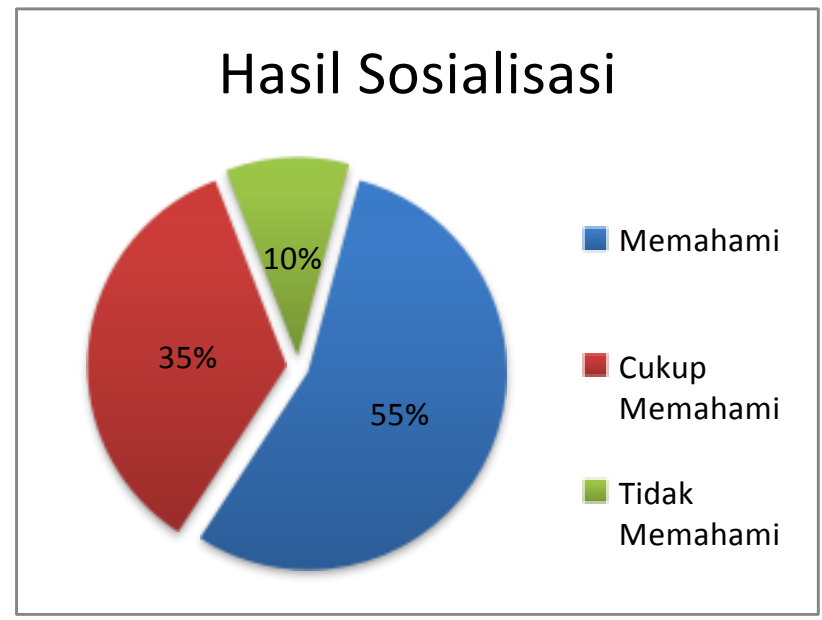

Gambar 12. Prosentase Hasil Sosialisasi

\section{IV.KESIMPULAN}

Berdasarkan pembahsan di atas, dapat disimpulkan bahwa telah dilaksanakan pengabdian kepada masyarakat sosialisasi deteksi dini hama wereng menggunakan teknologi informasi di desa Cabean, Kecamatan Sawahan, Kabupaten Madiun. Untuk hasil yang didapatkan sebesar 55\% dari anggota kelompok tani dapat memahami materi sosialisasi dengan baik.

\section{UCAPAN TERIMAKASIH}

Terima Kasih Kepada Lembaga Penelitian dan Pengabdian Kepada Masyarakat Universitas Merdeka Madiun.

\section{VI.DAFTAR PUSTAKA}

Budiman, Arief., Amadi, Dwi, Nor., 2016, Development of Dhungkrek Dance Learning Application to Preserve Local Culture Existence, International Journal of Advanced Research in Computer Science Volume 7 Number 3.

Mulyawan, Sang., Budiman, Arief., 2013, Perancangan Aplikasi Pembelajaran Tentang Tindak Pidana Korupsi Berbasis Mobile, Seminar Nasional Teknologi Informasi dan Komunikasi - Universitas Atma Jaya Yogyakarta.

Stevani, L R. 2017. 233 Hektare Tanaman Padi di Madiun Terserang Wereng. Diakses pada 31 Desember 2018. https://jatim.antaranews.com/berita/195920/223-hektare-tanaman-padi-di-madiun-terserang-wereng

Triono, Joko., Tristono, Tomi., Expert System Identification of Pest and Diseases of Rice using Html5, International Journal of Advanced Research in Computer Science Volume 7 Number 3. 